\title{
Magmatic architecture of continental flood basalts - a Deccan Traps perspective
}

\author{
TUSHAR MITTAL ${ }^{1}$, MARK RICHARDS ${ }^{1,2}$, NOAH RANDOLPH- \\ FLAGG $^{3}$ \\ ${ }^{1}$ EPS Dept. UC Berkeley, Berkeley CA 94720 \\ *correspondence tmittal2@berkeley.edu \\ ${ }^{2}$ Dept. of Earth and Space Sciences, UW, Seattle, Washington, \\ USA \\ ${ }^{3}$ USRA, Dept of Exobiology, NASA Ames Research Center
}

Flood basalts represent some of the largest magmatic events in Earth history, with intrusion and eruption of millions of $\mathrm{km}^{3}$ of basaltic magma over a short time period ( 1-5 Ma). A typical continental flood basalt (CFB) is emplaced in hundreds of individual eruptive episodes lasting decades to centuries with lava flow volumes of $10^{3}-10^{4} \mathrm{~km}^{3}$. These large volumes have logically led to CFB models invoking large magma reservoirs $\left(>10^{5}-10^{6}\right.$ $\mathrm{km}^{3}$ ) within the crust or at Moho depth. In the last few decades, significant improvements in geochronological, geochemical, paleomagnetic, volcanological, and paleo-proxy measurements have provided high-resolution constraints on CFB eruptive tempo - the volume, duration, and frequency of individual eruptive episodes. Here, we use a new volume-averaged visco-elastic mechanical model for an ellipsoidal magma reservoir coupled to a dike-shaped erodible conduit to calculate how eruptive fluxes $\left(\mathrm{km}^{3} /\right.$ year$)$ and volumes vary as a function of reservoir geometry and crustal properties for a single magma reservoir, as well as multiple connected reservoirs. We use a 1D thermal model and characteristic timescales for magma reservoir evolution to model how crustal visco-elastic properties evolve over time during the emplacement history of a CFB event, and how they impact magma eruptibility. Using the well-studied Deccan Traps as an archetype for CFB systems (along with datasets from other CFBs), we find that the presence of just a few large crustal magma reservoirs is inconsistent with the observations. We instead propose that CFB eruptions are fed from a number of smaller $\left(\sim 10^{2}-10^{3.5} \mathrm{~km}^{3}\right)$ interconnected magma reservoirs present throughout the crust. This magmatic plumbing architecture leads to; (a) large volume efficient eruptive episodes with 10-100s of years duration; (b) relatively short time-periods (1000s of years) separating eruptive episodes since multiple mechanisms can trigger eruptions (e.g., magma recharge or volatile exsolution); (c) lack of large uppercrustal intrusive bodies in geophysical datasets; and (d) marked geochemical changes between and within individual eruptive episodes as observed in various CFB sections. This new model has important implications for the timing and volumes of climatealtering volatile emissions associated with CFBs. 